\title{
FAMILIA Y EDUCACIÓN EN CUATRO MIEMBROS DE LA GENERACIÓN DE 1927: CANSINOS ASSENS, CORPUS BARGA, M. FERNÁNDEZ ALMAGRO Y R. GÓMEZ DE LA SERNA
}

\author{
POR \\ José Manuel Cuenca Toribio \\ Soledad Miranda García \\ Madrid
}

\section{RESUMEN}

En este artículo se analiza la infancia y educación de estos cuatro escritores de la generación de 1927 por medio de los relatos biográficos, intentando fijar la importancia de la misma en su producción y formas de comportamiento posterior.

\section{ABSTRACT}

This essay analise the childhood and educational period of these 27 Generation's four writers trhough their biographies, trying to fix the importance of these aspects in their literature and later behaviours.

El territorio de la infancia y la mocedad es, sin duda, el que proporciona datos más sólidos y nutridos para el análisis de la familia y la educación a nivel singular y generacional. La porosidad de la inteligencia y el espíritu en los primeros quince o veinte años determinará que las experiencias y mores familiares guarden un permanente valor de referencia, así como los modelos educativos interiorizados, por asunción o rechazo, de la misma edad de la existencia humana. De ahí, por tanto, que sean dichos años los que imanten con mayor fuerza el afán de reconstructor de la vida colectiva y también, en el caso del biógrafo, del investigador de un destino excepcional o notable entre sus 
coetáneos. En España, precisamente este planteamiento metodológico adquirió importancia sustantiva en las ciencias del hombre con las meditaciones orteguianas en tomo al concepto de generación divulgado en Francia por Dilthey y su escuela. Los intelectuales objeto de nuestro análisis aceptaron sin mayores reservas la validez de este instrumento, bien que su adscripción a las generaciones de1914 o 1927 en las que cabe incluírsele, especialmente en la segunda, no suscitaba en ninguno de ellos particular preocupación ni atención'.

Al elenco de los autores aquí estudiados cabría articulársele en dos binomios, andaluz: Rafael Cansinos Assens (1883-1964) y Melchor Fernández Almagro (1893-1966), y otro madrileño: Corpus Barga, seudónimo de Andrés García de la Barga (1888-1975) y R. Gómez de la Serna, aunque uno de los integrantes del último tuviera también estrechos lazos con el territorio andaluz y, a sensu contrario, los meridionales se aclimataran pronto en la capital del país, a la que profesaron un rendido culto sentimental, sin renunciar por ello a sus raíces.

Esta ligera diversidad regional no se ve acompañada en el terreno social, ya que, en cuanto a su extracción, la nota burguesa será un elemento unificador de todos ellos, salvo, parcialmente, en el caso de uno de los dos o tres mejores traductores de la España del siglo XX: Cansinos Assens. Burguesía capitalina con fuertes vínculos agrarios, mas muy abierta al mundo de la cultura y sensible a todas sus manifestaciones. Sus hogares formaron parte del muy atractivo a la vez que exiguo núcleo de las élites intelectuales alumbradas por la Restauración, que dieron tono al indudable esplendor de la llamada edad de plata, bien que no lograran, sin embargo, imponer su estilo de vida al conjunto de la clase en que se integraban y cuyos vicios y defectos provocaron la repulsa de los grandes escritores de la época, como Galdós y Palacios Valdés. Cansinos se convierte igualmente en este extremo en una excepción, siquiera leve. Pues,

1 Pese al bataneo repudiador que con frecuencia se hace del método aclimatado entre nosotros por Ortega, es claro, sin embargo, que sus argumentos y, sobre todo, la elaborada teoría de su más filial discípulo, Julián Marías, no pueden facilmente vapulearse con simples referencias a su elitismo. Usado con moderación y sin pretender pasar toda la realidad histórico-social a través de su cedazo, el planteamiento general puede rendir valiosos servicios. Vid del último autor citado El método histórico de las generaciones. Obras completas Madrid, 1970, VI, en especial 125 y ss. Depurado de su ganga encomiástica tal vez pueda suscribirse cl juicio de R. Pérez Delgado."Y véase ahora cuantas dificultades presenta la recta utilización del concepto generación histórica, concepto en principio eminentemente sociológico, no precisado todavía, aunque ya suficientemente claborado y por fortuna pensado y expuesto a la lengua española, c interpretado de modo ejemplar por Julián Marías en su excelente libro El método histórico de las generaciones, y utilizado fundamentalmentc por Ortega en toda su obra". "Generaciones fallidas", cn Homenaje a Ramón Carande. Madrid, 1963, III, 234-35 Por ct contrario una demoledora crítica de este método en FERNANDEZ DE LA MORA, G., Ortega y el 98 Madrid, 1961, 39-40. Y, en fin, una postura más matizada es la de MORON ARROYO, C., El sistema de Ortega y Gasset. Madrid, 1968, 285-90.

La iglesia de los últimos siglos

Hispania Sacra 50 (1998) 
en efecto, huérfano de padre desde muy niño, encontró tanto en su madre - de ardiente religiosidad- como en su tío y tutor - - "republicano y masón (durmiente) - aliento efectivo para desarrollar una precoz y desbordada vocación por las letras y la escritura. Los reducidos medios económicos de su familia, perteneciente a las clases medias urbanas, no significaron obstáculo para desplegar, como decíamos, sus envidiables dotes literarias ${ }^{2}$.

Fueron justamente los sacerdotes de la institución religiosa que guió en la Sevilla natal sus primeros pasos escolares los que atisbaron muy tempranamente sus altas cualidades para la poesía la Historia y el Arte. Y es este rasgo, la impregnación eclesiástica del despertar a la cultura de nuestros autores, otro poderoso elemento unificador de su universo mental. Aunque, salvo Cansinos, los tres restantes cursasen el Bachillerato en centros laicos o estatales, Jas primeras letras las aprendieron en establecimientos en los que la presencia de la Iglesia era absorbente. Característica, por otra parte, similar y común a la casi totalidad de las figuras intelectuales de su tiempo, militantes con posterioridad en buen numero de casos en las filas de un anticlericalismo más o menos radical, senda no seguida, el menos con firmeza y tenacidad, por ninguno de nuestros autores alejados sin estridencias en su madurez de la fe infantil.

Un catolicismo aceptado sin angustias ni traumas, una madrugadora inclinación por el mundo de las letras y una familia bien trabada dará a los autores ahora analizados un universo de certezas en los días de su infancia, que dejará, lógicamente honda huella en una trayectoria ulterior, configurada por las zozobras y trasgos propios del oficio del pensamiento. Todos $-\mathrm{y}$ en este punto radica tal vez su común denominador más peraltado- se instalaron gozosa y plenamente en su infancia y familia, de la que, importará insistir, aceptaron tradiciones, normas y objetivos. En todos, la primera etapa de la vida transcurrió dentro de un ambiente lleno de posibilidades y abierto a cualquier aventu$\mathrm{ra}$, en un clima de ordinario alegre y positivo, aunque no panglosiano. Las expectativas desatadas por la llegada de la última centuria del segundo milenio con su cohorte de inventos espectaculares abonaron en imaginaciones atraídas casi desde la cuna por lo novedoso - recuérdese el caso de Gomez de la Serna

2 "Aquella consagración del viejo poeta, que a nosotros entonces nos parecía un genio, confirmó en mí la vocación líteraria y me valió, a mis trece ańos, el entusiasmo de mi madre, la tolerancia de mi tío y el epítclo de literato en la familia y entre sus amistades [...]. Sobre todo me apasionaba el estudio de los idiomas, desde que en la clase de Latín descubrí que no cra el español la única lengua que habian hablado y hablaban los hombres, y que había libros ante los cuales el hombre más culto podía encontrarse en la triste situación de un analfabeto. Y, como quería leerlo todo, adquirí el don de lenguas de los apostoles, poseer la clave de todos los enigmas, y así completaba en casa, durante los veranos, los parcos conocimientos de lalín y francés que nuestros profesores nos habían dispensado, traduciendo a los clásicos de ambos idiomas". La novela de un literato. (Hombres-Ideas-Efemérides y Anécdotas...). (1882-1914) Madrid, 1982, 16-17. 
y el más prosaíco, pero no menos imantado por los asombrosos descubrimientos de fin de siglo de Fernández Almagro- el terreno más favorable al ensueno y la fantasía.

El fin del canovismo marcó este horizonte. Si la calma chicha de la primera Restauración presidió los años inciales de su existencia, ésta pronto se vería remecida por los remolinos del Desastre. Es a tal respecto muy ilustrativo comprobar cómo en sus espíritus tremantes la tragedia del 98 se colaría de rondón a través de imágenes impresionadas por retinas muy sensibles y de conversaciones familiares oídas con acezante curiosidad por unos niños en los que los asuntos públicos despertaban, sin duda con asentimiento de sus educadores, una vivaz atención. Más tarde, al redactar sus memorias y autobiografías, dedicaron amplio espacio a reconstruir algunos lances presenciados en las calles de Granada o Madrid en la onda abierta en la conciencia nacional por la pérdida de los áltimos territorios ultramarinos.Corpus Barga, el más moroso de todos ellos, describirá con una riqueza de detalles que convierte a sus páginas en verdadeera fuente para aquel capítulo de nuestra historia, a personas y ambientes estremecidas por un patriotismo de la mejor ley. $Y$, aunque no alude a ello en sus apasionantes recuerdos, es harto probable que su inclinación por el estudio de la España contemporánea y, de manera particular, por el orto y ocaso de su Marina moderna, se despertase en Fernández Almagro al calor o bajo el influjo de los acontecimientos del $98^{3}$. Incluso en el espíritu más estrictamente literario y artístico de todos ellos, en el creador de las greguerías, entre

3 "Pero he aquí otra palabra que oía sonar y resonar en la tertulia de casa como un viento que todo lo sacudiera y de la que se apoderaron los niños más adelantados para llamarse de otra manera, en sus juegos de policia y ladrones, de cristianos y de moros, de cartagineses y romanos. Ahora jugaban a españoles e insurrectos o yanquis. Porque la palabra sobrevenida, para mi, fulminantemente, cra ésta: "Cuba". Seguramente que se hablaría también de Filipinas; pero yo no ó́a otra cosa que Cuba. - ¿Cuándo se llevan a Salvador para Cuba...?

- ¿Le tocará a Pepe ir a Cuba...?

- ¿Estará ya Emilio en Santiago de Cuba...?

Salvador, soldado de infantería, era criado de mi abuelo, y su marcha a Cuba con batallón del Regimiento de Córdoba se pierde en lejanas brumas, de las que solo emergen, con referencia a ese momento y a otros posteriores el bullicio de las calles y las notas de color rojo y amarillo, de seguroen colgaduras y banderas, en botoncitos, lazos, cintas, escarapelas, moñas, en el pecho o en la cabeza de las mujeres y en las solapas de los hombres... Por el concierto que la banda del Regimiento de Córdoba dedicó a mi tío Pepe Corral, ascendido a coronel, y por el comentario de toda mi familia a la harenga de mi primo Melchor, ya adolescente, a una de las manifestaciones patrióticas de aquellos días, desde un balcón de El Defensor de Granada, me es dado revivir la emoción de las Guerras de Ultramar, en tenues resonancias de lejanos compases de marcha militar; la de Cádiz, seguramente. Y para adquirir, a su vaga e indirecta manera, la emoción del desastre final coincidió la noticia de que tío Ennilio habia salvado la vida en un combate, con el naciniento de mi hermana Asuncion". Viaje al siglo XX Madrid, 1962, 52-53. Vid CuENCA TORIB10, J. M., "Notas para el análisis de la cultura intelectual andaluza del siglo XX (Primera parte)" en Córdoba, apuntes para su historia. Cordoba, 1981.

La iglesia de los últimos siglos

Hispania Sacra 50 (1998) 
bromas y veras, su evocación de dicha etapa contiene casi todos los elementos del manual del buen regeneracionista.

Al margen de impresiones particulares, sus años bachilleriles transcurrieron en el ambiente conformado por el citado episodio. Con mayor o menor intensidad, comprendieron que una España crecientemente problematizada enmarcaría ya toda su existencia. En unos, desde el plano de la cultura, y en otros, desde el de la política, este planteamiento cobró muy pronto fuerza. Pertenecientes a la élite del poder de la Restauración, las familias de Corpus Barga y Ramón Gómez de la Serna, emparentadas por más de un vínculo, vivieron en toda su crudeza el desgarro provocado por la crisis del 98 en los cuadros dirigentes del país, asumiendo plenamente tal experiencia dichos autores. Así, a pesar de su ánimo aparentemente desenfadado y del estilo sub specie aeternitatis de la Automoribundia, Ramón no podrá ocultar la desesperanza española y la frustración íntima provocada en su ánimo por el doloroso final del cursus honorum de su padre, en el instante mismo en que acariciaba la idea de regentar una cartera ministerial en el segundo gobierno canalejista. A su vez, introducido muy pronto en las redacciones de los periódicos radicales del fin de siglo madrileño, Cansinos, de clara vocación y entrega a las lenguas y a la literatura, sentirá por un momento el torcedor de su decidido proyecto literario el contemplar un país que parece haber perdido el rumbo de la modernidad e incluso de su propia entidad ${ }^{4}$.

La política, factor con frecuencia escisionista en todos los grupos humanos, no fue percibida así en la niñez y primera juventud de los autores comentados. Los tres que centran casi específicamente nuestro interés - ya que abstracción hecha de su "atipicidad", Cansinos no dedicará a los años de formación apenas si una veintena de páginas de sus fluviales memorias-, la vida pública se le

4 "Por los demás, en aquelio días vesperales de la pérdida de las colonias, to que absorbia la atención pública y llenaba las planas de los periódicos no era la literatura, sino la política. Eran días de intensa agitación, de violentos discursos en el Parlamento, de exaltados artículos patrióticos en la prensa y manifestaciones calejeras [...] Como todos los jovenes de aquella época yo tambien participaba de aquella fiebre general, formaba en las manifestaciones gritando: "¡Viva España con horra!", e iba a la estación del Mediodía -aquélla por donde había entrado en Madrid- a despedir a los soldados que marchaban a la guerra, ebrios de entusiasmo y de vino, sudorosos, apretujados en los coches rebosantes, por cuyas ventanas asomaban botellas y guitarras, y pañuelos, en tanto el tren se movía lentamente a los acordes de la Marcha de Cádiz, coreada por el público. Eran los días del chinchín, tan motejado y ridiculizado después del Desastre [...] Vino luego el desastre colonial y la reacción consiguiente en la opinión pública y en el tono de los escritores [...] Empezaron a sonar nombres desconocidos, que ya no eran los de Galdós, Pereda, Valera y Coloma, sino los de Martínez Ruiz, Baroja, Salvador Rueda, Valle Inclán, Rubén Darío, no todos al mismo tiempo, pero unidos en una sucesión estrecha, como salvas de una misma descarga contra todo lo viejo, contra todo lo anterior a] Desastre, que la protesta juvenil confundía en el mismo anatema, sin hacer distinción entre lo político y lo literario". La novela de... 19-20. 
apareció desde un primer instante plural y contrastada. Corpus Bargas, Ramón y Fernández Almagro pertenecieron a familias en las que los padres fueron elementos significados del Partido Liberal en sus facciones más vanguardistas, y es natural, por ende, que absorbieran el espíritu tolerante que impregnaba sus hogares, en los que las mujeres propendían a posiciones más conservadoras. A esta actitud coadyuvó de una manera señalada la instrucción recibida en escuelas, colegios e institutos, con un neto predominio de las posturas mesuradas, incluso, en los de tutela eclesiástica. Es curioso destacar en este plano que las opciones ultramontanas e integristas, tan en boga en la época en los medios sociales a los que pertenecían nuestros autores, apenas si se vislumbran en las páginas de su literatura memoriográfica, tan puntual en los casos de Barga y Fernández Almagro.

Por el contrario, republicanos y radicales, comparecen con asiduidad en ella, como trasunto fiel de la transigencia y pluralismo de sus entomos familiares. A tal respecto, se constata en su descripción las inclinaciones republicanas y las preocupaciones sociales, de la profesión galénica, tan difundidas por la gran novela del momento. En este punto son en extremo curiosas las relaciones mantenidas entre los progenitores de Femández Almagro y el rector granadino D. Eduardo García Duarte y su hijo Rafael, médico como él, así como con los padres de Francisco Ayala, cuya madre, cultivada y sensible, era hija del primero ${ }^{5}$.

La crisis monárquica arreciada con el 98 no mermó la fe en la institución real de la familia de nuestros autores, que no dejaron de sentir cierto atractivo por el joven Alfonso XIII, adalid por aquellas fechas de una España nueva...6. Pese a lo cual, como gentes de otra generación en contacto con elementos claramente de afectos al régimen, el monarquismo de nuestros autores se nos aparece en la época acotada en estas páginas asaz tibio, como premonición en algunos de ellos de un republicanismo ardoroso, bajo cuyas banderas se alistaría muy precozmente Cansinos?

s "La suma atracción de nuestra nueva casa estaba constituída para mi por una señora joven, verdaderamente cncantadora, Luz Duarte, hija y hermana de los médicos de casa [...] Era una mujer singular por su inteligencia y cultivada sensibilidad [...] Leía cuanto le era posible y me prestaba los libros que por algún motivo pudieran interesarle". FERNÁNDEZ ALMAGRo, M., Viaje al siglo..., 207. Otro retrato de esta dama es el de su hijo AYALA, F., Recuerdos y olvidos. Madrid, 1982, 30.

6 "Y es que [...] dificilmente podrá ser comprendido Alfonso XIII si no se le enmarca en la promoción generacional del 98." SECO SERRANO C., Alfonso XII y la crisis de la Restauración. Madrid, 1979, 62.

7 "Me encantó ver al rey, tan scncillo, simpático y risueño como ya le había visto en Madrid, solo que ya nada nin̄o: desde mis diez años Alfonso XIII, con sus diez y ocho años, me pareció un hombre hecho y derecho. Tenía fama de llevarse a la gente de calle y esta frase se haría literalmente efectiva, porque la muchedumbre, sin respeto alguno al orden del desfile, se sentía atraida por la franca sonrisa y la mirada alegre de Alfonso XIII, y rodeaba y seguía su coche a lo largo del itinerario [...] Confieso que si el rey encendió mi fe monárquica presunta o de clavo pasado". FERNÁNDEZ

La iglesia de los últimos siglos

Hispania Sacra 50 (1998) 
El perfil familiar dibujado por nuestros memoriógrafos será el de una estructura extensa, en la que la consaguinidad y la gens alcanzarán un alto e indiscutible valor, y en la que los parientes de lazos más débiles formarán, por consiguiente, un solo conjunto con los familiares de más directa y estrecha vinculación, sobre todo, cara al exterior.Las familias más menesterosas de los núcleos integrados por los hogares políticamente influyentes de la mayor parte de nuestros autores verán en éste un escudo protector ante las adversidades; constituyéndose así una red clientelar nada despreciable a la hora de abrillantar los prestigios sociales del núcleo central y de reforzar su ascendiente y peso público.

No obstante la disparidad de ciertas opiniones y gustos en la célula básica familiar, ésta se mostrará mury compacta, moviéndose en ella con suma complacencia nuestros autores, que narrarán, con seducción por los matices, las mil y una peripecias de estas estructuras familiares - genealogía, heráldica, historia... La "sangre" era así un elemento muy cotizado en su entomo y reverdecido sin cesar con aniversarios, cumpleaños y festividades varias, celebradas por lo común de forma masiva. Su evocación pondrá una nota manriqueña en unos recuerdos en los que la melancolía dista de ser la nota destacada.

El repaso de linajes y estirpes llevado a cabo en la reconstrucción de dichas peripecias deja al descubierto $-y$ por enésima vez Cansinos no cuenta en esta acotación - que la niñez y la pubertad de nuestros autores han transcurrido, en general, en el ámbito de una sociedad heril, perpetuada en España por una tardígrada introducción en la contemporaneidad. La jerarquía vertebraría mansiones y menesteres, dando estabilidad a creencias y actitudes. La contestación o la protesta se dejaran oír muy aisladamente en la rememoración de estas vidas españolas, con la excepción nuevamente de Cansinos, aunque también en su caso asordinada y sin verdadero relieve. De la vigencia de la sociedad heril no podemos encontrar testimonio más expresivo que el protagonismo -en ocasiones, casi hegemónico- que ofrece en estadios muy dilatados de las memorias y autobiografias que nos ocupan, el estrato de los servidores domésticos, de los criados y criadas que pueblan herborosamente viñetas y retazos de los recuerdos infantiles de nuestros autores, con mención muy específica de los de Corpus Barga.

Su detallista pluma no escatimará recurso alguno para dibujar con precisión intimista el papel decisivo que tenían en su medio familiar los criados, en su doble versión urbana y rural. Verdaderos deus ex machina en los momentos de mayor tensión entre padres e hijos, su papel y función están observados por un

ALMAGRO, M., Viaje al..., 187-88. Tal sentimiento se trocaría llegada la madurez en otro mucho măs severo hacia el mismo monarca según lo patentiza su Historia del reinado de Alfonso XIII, aparecida en 1934, muy alejada tanto de aquellos ardores infantiles como de los de su recobrado monarquismo de la senectud. 
demócrata a natura desde un ángulo muy encomiástico ${ }^{8}$. Casi todos los miembros de dicho estamento estaban por completo integrados en la familia, preocupándose de su fortuna y solidez, y mostrándose en toda ocación solícitos, en particular, con la grey infantil, de la que se convertían en muchas ocasiones en sus auténticos educadores. Criados y criadas instruían a los niños en las llamadas, por los institucionistas, "lecciones de cosas", y les enfrentaban con las realidades cotidianas, poniendo, a las veces, un celaje ante sus aspectos más desagradables. Este mundo tenía sus propios valores, muy aplaudidos por Corpus Barga o Melchor Fernández Almagro, de manera semejante, como es sabido, a otras muchas plumas burguesas del mismo periodo, como por ejemplo, la de D. Ramón Carande 9 . Hasta los famosos bandoleros de Sierra Morena formaban parte de este curioso universo. X, así, la familia de Corpus Barga llegó a tener uno a su servicio particular, especialmente consagrado a conducir, sin peligro alguno entre los vericuetos de aquella fragosa geografía, a los jóvenes que, llegada la estación de los estudios, abandonaban sus vacaciones estivales pasadas en la Sierra cordobesa, en la tierra de los Pedroches, para trasladarse a la Villa y Corte ${ }^{\text {to }}$. Los extremos se atraen, a las veces. Símbolo máximo de la seguridad burguesa del mantenimiento de un orden propicio a los intereses quiritarios, la Guardia Civil acuđiría también con cierta frecuencia a los puntos de la pluma de alguno de nuestros memoriógrafos, que intentarán recoger con exactitud la tranquilidad que embargaba a progenitores y deudos cuando, en momentos de agitación o temor, veían relucir los acharolados tricornios.

Pero al despertar a la vida nuestros autores, el beaux vieu temps de una clase híbrida, poco concienciada de su vigor y misión y atraída siempre por el estilo y maneras de la aristocracia, era ya una realidad para muchos de sus componentes.

8 Entre los muchos pasajes que pueden antologizarse elegimos este por creerlo muy representativo: "Alli me enseño el boquete que habían tenido que abrir los bomberos en la pared que daba a la alcoba de éstas [sus hermanas]: "ha dicho tu padre que te asomes al boquete y mires lo que has hecho", me hizo saber el bueno de Amancio en un tono desacostumbrado y por ello dejé de notar su acento gallego; miré el efecto, y ví un revoltijo de ropa quemada y mojada y un montón de trozos de madera ennegrecida [...] Amancio cortó esta contemplación para seguir informándome ;"Ahora tengo que encerrarte en un cuarto oscuro, lo ha mandado tu padre, te encerrare en el cuarto en que no haya ratones y no me iré lejos, estaré con cuidado, si tienes miedo me llamas". A lo largo de mi vida he estado, como tantos españoles y millones de europeos, varias veces en la cárcel y siempre que me han encerrado en el calabozo, el gesto antipático de oír (es un gesto que se oye) echar la llave del cerrojo al carcelero ha tenido en mis resonancias tiernas, me ha parecido siempre que era Amancio quien me encerraba pero se quedaba detrás de la puerta". Los pasos contados. Una vida española a caballo de dos siglos (1887-1957). 1. Mi familia. El mundo de mi infancia, Madrid, 1980, 224.

9 Recuerdos de mi infancia. Madrid, 1987, en particular 31-2.

to Vid Cuenca Toribio, J. M., Visión de Andalucia. Granada, 1983. 
El más genial de todos los autores glosados en las presentes páginas, Ramón, capta con fuerza la escisión anímica que desazonó a esta alta burguesía ilustrada en el cruce de una a otra centuria. Deseosa de ensanchar el paralaje mental de la sociedad alfonsina, se debatió a partir de las mudanzas desencadenadas por el Desastre y el fin de la Regencia, entre esta sincera aspiración y su nostalgia del buen orden burgués, nostalgia que para muchas familias de este estrato se acrecentó ante su irreparable postración económica. "En algunos de aquellos hogares de Madrid de últimos y primeros de siglo había una seguridad en la vida que no he vuelto a encontrar -más que mucho más tarde en algunos hogares de América-, y es que el comedimiento en el pensar y el sentir, en el ser lógico y considerado, en el tener en cuenta a los demás y estar cada uno en su sitio, eran prodigios del asentamiento de la vida. El presupuesto de la relación con los demás y de la relación privada estaba trazado en cuentas exactas, previsoras, echadas con el lápiz de la honradez minuciosa que exigía en el día o en el mes los más imprescindibles sacrificios"'!!

Es conocido como en el horizonte de los orígenes de la contemporaneidad la escuela y los educadores ocuparon un puesto de primacía en la formación del espíritu nacional, convertido, a las veces, en una religión secularizada. España no constituyó excepción dentro de este fenómeno general; sin que, por fortuna, el nacionalismo hispano revistiese la fisonomía reluctante o degradada de los movimientos racistas y de los fundamentalismos mesiánicos. En todos los establecimientos docentes en los que cursaron sus estudios nuestros autores $\rightarrow$ no fueron escasos - un patriotismo grandilocuente, reactivado por la crisis ultramarina, enmarcó de ordinario sus primeros pasos educativos, sin suscitar repulsa especial por parte de ninguno.

"Madrid, 1974, 138. Su mejor biografo, GOMEZ DE LA SERNA, G., ha recogido insuperablemente el fondo rocoso de un artista puro: "En ese piso tercero de la calle de la Corredera permaneció la familia hasta que el aĩo $1898 \mathrm{el} \mathrm{mal} \mathrm{viento} \mathrm{del} \mathrm{Desastre} \mathrm{la} \mathrm{desplazó} \mathrm{a} \mathrm{una} \mathrm{lejana} \mathrm{orilla} \mathrm{provincial.}$ Pero de esos diez primeros affos, sale el niffo Ramón bien cuajado en la solera de aquella honesta burguesía madrileña acomodada sin pretensiones en lo que parecía sólida balaustrada del vivir. De ella perduraría a lo largo de todas las rebeldías y por debajo de todas las ejercitaciones fuera de scric de la bohemia de afición y de la genialidad nativa, la finura del alma, el poso fundamental de Jas creencias básicas y el talante insobomable de su honradez ante la vida". Ramón (Obra y vida). Madrid. 1963, 28-8. Por otra parte, acaso ningún hecho demuestra con mayor patencia el estado de ánimo a que aludjamos en el texto que el de la propia valoración de las enseñanzas recibidas al dejar atrás la niñez. Las grietas aparecidas en el patrimonio de los García Barga en los umbrales del siglo actual motivaron, por ejemplo, que nuestro autor, a diferencia de su hermano mayor -alumno del prestigioso internado de los Escolapios de Hortaleza -, estudiase la segunda enseñanza en un centro laico. La educación recibida en éste que hoy se nos parece como muy plausible, fue vista entonces por el gran periodista como inferior a la impartida en los colegios de alto copete. Cfr. Los pasos contados... 2.Puerilidades burguesas. Madrid, 1979, 48-65. 
Como tampoco lo harían respecto a los sistemas pedagógicos, y sobre todo, en cuanto al contenido de las enseñanzas. Globalmente, unas y otros merecieron una notable calificación por parte de inteligencias ciertamente agudas y perspicaces desde la infancia. Sin ocultar deficiencias y lagunas, tanto los profesores como las disciplinas arrojaron a la hora del balance un saldo positivo. En la mayor parte de los últimos, la entrega y la competencia - según los diversos grados, claro es - se ofreció a sus alumnos como indiscutible, indicándose en más de un caso la actualización de conocimientos y técnicas, tal y como, por ejemplo, relatara Corpus Bargas al rememorar su estancia en el centro privado en que cursara el Bachillerato, y en el que, entre otros destacados docentes se encontraban los sevillanos hermanos Barnés. En punto a las materias y textos su juicio fue también, repetiremos, aprobador; aunque no faltasen, conforme es lógico, reservas y críticas cara a ciertos tratados y manuales así como frente a la cansina u obsoleta pedagogía imperante en algunos cursos y clases. Espíritus alertados, intuyeron la lenta pero profunda e irrefrenable revolución escolar que se operaba en España en el tránsito de uno a otro siglo, como siembra de la que se entrojarían algunas de las mejores cosechas de nuestra vida colectiva en el primer tercio del siglo XX.

Las continuas lecturas y la gran movilidad geográfica de la niñez y puericia de la mayor parte de nuestros escritores les proporcionaron, junto con una atmósfera familiar muy permeable a lo exterior, una imagen notablemente diversificada y plural en su nación. Cimiento de su espíritu y cultura, tal enfoque estaría presente en su adultez en buena parte de sus talantes y trabajos, poco proclives al sectarismo, a pesar de las decididas acciones políticas de algunos de ellos. En ciertos casos, v. gr., en el de Ramón, dicha versión nutriría a su pluma de una gran apertura de registros para acercarse con intención integradora a las figuras más representativas de las letras y política de la España contemporánea. Y no fue otro el propósito que albergó Fernández Almagro en sus esfuerzos por reconstruir, en la última fase de su existencia, el mundo de la Restauración sine ira e cum studio, recuperando parte de la gran tradición liberal española ${ }^{\mathrm{i}}$.

Uno de los extremos axiales de su formación, de la recibida en el círculo familiar y la asimilada en los centros educativos a que concurriera en su niñez y adolescencia, fue una visión nacionalista y acrítica del pasado de su país. En su cosmovisión tal imagen se erigió como un bloque de granito que contribuyó decisivamente a nuclear toda su personalidad. Aunque en la madurez sometieran a una profunda revisión los esquemas de la primera edad, mutándolos por un patriotismo crítico y una versión antitópica de la historia española, sus es-

12 CuENCA ToRiBio, J. M., Semblanzas andaluzas. Galería de retratos Madrid, 1984, 55-8.

La iglesia de los áltimos siglos

Hispania Sacra 50 (1998) 
critos y actos dejan ver una asunción entusiasta de los valores y aspectos positivos de unos de los grandes pueblos de Europa. El contacto americano en el ejemplo de los escritores madrileños y la atención hacia todolos concerniente a los antiguos territorios españoles por parte de los andaluces, reforzará en todos ellos la aceptación de la historia patria en sus dimensiones más fecundas.

En el binomio menos atraído por los aspectos y estudios históricos, el compuesto por Ramón Gromez de la Serna y Cansinos Assens, sus referencias al pasado nacional no serán infrecuentes ni descalificadoras, contemplando con simpatía el énfasis con que sus maestros y mayores intentaron inculcarle un conocimiento detenido y orgulloso de sus raíces colectivas. Más crítica en Corpus Barga; más calurosa en Fernández Almagro, esta misma concepción latirá en toda la vasta producción de ambos, mostrándose igualmente agradecidos a las enseñanzas que en la materia asimilasen en la niñez y pubertad.

En buena medida, su fe en los destinos de una nación que había sido en sus mejores épocas poderoso agente de creación y transmisión culturales, les serviría para no abismarse en el pesimismo en los días en que la guerra civil pondría a dura prueba convicciones e ilusiones, señalando un punto y aparte en su vida. Pues, en efecto la tragedia de 1936 precipitó a la existencia de nuestros cuatro autores por derroteros imprevisibles e inimaginables en una niñez y adolescencia cuajadas de frutos, al tiempo que penetradas de confianza en el quehacer de su generación y en la andadura social y, sobre todo, cultural de un país por entonces muy creativo y dinámico. Pocas generaciones españolas, con la relevante excepción de la de los afrancesados, sufrieron ciertamente una escisión y ruptura más totales que aquella a la que pertenecieron los intelectuales que nos ocupan. El exilio americano en el caso de los madrileños adelantado y enmascarado, pero tan terrible como todas las expatriaciones en el caso de Ramón- y el exilio interior --mucho más doloroso y duro en Cansinos Assens que en el acomodaticio Fernández Almagro- encontró un lenitivo en la pasión española que les acompañó a todo lo largo del viaje de su vida: un viaje en el que su extensa cultura y solidaridad con los hombres de todos los tiempos y países les otorgaría el pasaporte de ciudadanos universales ${ }^{13}$.

13 Cfr, en particular, 50-1, 58-9 y 150-51. 